\title{
Cancer survivorship and work: Symptoms, supervisor response, co-worker disclosure and work adjustment
}

\author{
Joanna Pryce $\cdot$ Fehmidah Munir $\cdot$ Cheryl Haslam
}

\begin{abstract}
Introduction: Recent improvements in cancer treatment have not only increased cancer survivorship but also peoples' ability to work during and following treatment. However, the impact that both diagnosis and treatment has on cancer survivors' ability to fully engage in paid work is not yet entirely understood. This study aims to explore the role of symptoms, work adjustments and cancer disclosure to supervisors and co-workers on working during primary cancer treatment and return to work following treatment.

Method: 328 cancer survivors responded to a 33 item questionnaire that assessed cancer-specific variables e.g. type and treatment, symptoms experienced during and following treatment, disclosure of cancer and adjustments and supports available at work. Multivariate logistic regressions were run to determine the association of symptoms, disclosure and work adjustments and working during treatment and returning to work following treatment.

Results: The findings indicate that opportunities to work flexibly ( $\mathrm{OR}=2.43, \mathrm{CI} 1.21-4.02)$, disclosure to colleagues $(\mathrm{OR}=3.03, \mathrm{CI} 1.28-8.19)$, difficulties managing fatigue $(\mathrm{OR}=2.08, \mathrm{CI}$ $1.22-3.85)$, and paid time off to attend all medical appointments $(\mathrm{OR}=.4, \mathrm{CI} .30-.87)$ were associated with continuing to work during treatment. Correlates of return to work included difficulties managing fatigue ( $\mathrm{OR}=1.49$, CI 1.42-6.18), managing the stress of cancer $(\mathrm{OR}=2.80$, 1.05-5.34), managing physical changes associated with cancer (OR=.46, CI .13-.95), received advice from their doctor about work $(\mathrm{OR}=1.47$, CI 1.09-2.84) and return to work meeting with employer (OR 1.99, 1.2-5.09).

Conclusions: This study highlights the importance of symptom management in cancer survivors who work and the potential impact of workplace adjustments on the ability of cancer survivors to navigate in the world of work.
\end{abstract}

Keywords Cancer . Work . Management . Guidance . Rehabilitation 
Introduction It is estimated that 90,000 new cases of cancer are diagnosed in people of working age each year in the UK alone [1]; over a million cases in the US [2]. Advances in drug treatment now mean that cancer is shedding its status as a terminal illness and is increasingly perceived as a chronic disease requiring treatment, lifestyle change and monitoring [3]. Recent reports suggest that adult survivorship is on the increase [4], most notably within colorectal, breast, testicular cancer groups [2]. As a result, this means that more people continue to resume their everyday life during or following treatment. This includes remaining in or returning to employment. The effects of cancer and its treatment are by no means uniform [5], which currently make it difficult to generalise about the impact cancer and its treatment has on work. However, it is likely that some commonalities may be seen between cancer survivors to help formulate guidance for those working with or returning to work following cancer.

The employment status of cancer patients and survivors has important implications for society and the labour market, for organisations, and for the individuals and their economic, social and psychological health. Data suggest that approximately $62-84 \%$ of cancer patients return to work following treatment, with similar patterns found across European countries, Canada and the United States [5-8]. Despite this growing body of research in the area of cancer and work, very little is known about the specific psychosocial factors affecting continuance and return to work [9]. For example, there is limited information to inform cancer survivors about the possible impact of cancer, its treatment and long term side effects on work. There is also limited information on the work adjustments that can be made available and how to access them; when and how to manage exit from work and return to work; or supporting cancer survivors in managing work relationships. It is not surprising that many people with cancer remaining at work throughout treatment or returning to work, experience difficulties in managing their work due coping with physical changes, emotional pressures and fatigue associated with cancer and its treatment without adequate work-related support [3]. With the increase in cancer survivorship there is a need to address the quality of working life of cancer survivors. Healthcare and rehabilitation professionals could play a pivotal role in supporting this aspect of cancer survivorship. Effects of cancer, its treatment and ability to work

Research in the area of cancer and work has typically focused on employability statistics, adopting a health economic perspective (for example [3,10]), and more recently, the employment pathways of cancer survivors [7]. In their study, Short and colleagues identified that whilst one in five survivors reported cancer-related disabilities at follow-up, half continued to work. Furthermore, $13 \%$ of all survivors had withdrawn from work for cancer-related reasons within four years. The effects of cancer and its treatment that are likely to impact on an individuals' ability to work are many, and may present in combination. These include physical factors related to the disease (e.g. disfigurement or pain following surgery, [10, 11]), fatigue [12], cognitive functioning [13, 14]; and need for transportation $[8,15]$. Importantly, many of these side effects and consequences of cancer and its treatment may be more enduring and may last for many years post treatment. Many of the physical and cognitive limitations are also seen in other chronic illnesses [16, 17], and there is an opportunity to draw from the wider sphere of rehabilitation to provide a useful steer for cancer survivors and for practitioners in supporting them through their treatment and rehabilitation.

Whilst it is widely recognised that work adjustments fall into three broad categories: Modi- fied physical load (e.g. reduced weights in manual role or provision of supportive technologies), skill discretion (e.g. reorganisation of work) and time discretion (e.g. arranging home working or flexible working), a limited number of studies have examined the role of work adjustments specifically for cancer patients. Evidence suggests that, when an option, cancer survivors rely heavily on adjustments in time discretion, working reduced hours during and following treatment [18]. Whether adjustments to working time are a readily accessible 'default' option or an effective and appropriate adjustment remains to be understood. However, it does suggest that cancer survivors are not using the full complement of adjustments available to them. Drawing from the wider rehabilitation literature, the benefits of work adjustments can include improved illness management, psychological well-being and financial stability/independence [19]. 
Currently, it is not fully understood how cancer patients perceive their ability to work or the adjustments that are required to facilitate work during and following treatment. Studies that have attempted to address these concerns continue to be hampered by small sample sizes and a lack of control for cancer site, and in-depth studies have been largely restricted to case study and qualitative research [5]. There is need to explore the prevalence of these issues in larger surveys and longitudinal designs to develop best practice and influence policy in cancer rehabilitation. In practice, health care practitioners make inferences based on the medical literature (e.g. the impact of treatment and its side-effects); information gleaned from learning through experience, or information obtained from cancer support organisations (for example; American Cancer Society or CancerBACUP). This highlights three problems: first, there is a lack of evidence-based research in cancer and work to inform reliable and valid guidance and by implication, an absence of advice [6]; second, it requires health care professionals and cancer patients to make conceptual leaps between side-effects and work limitations or disabilities; third, the support information available is largely restricted to guidance on the legal rights of patients or general work rehabilitation practices (that may not be applicable to cancer patients).

Whilst advances are being made to better understand the consequences of cancer on work, there is need to gain a better understanding of the work limitations experienced by cancer survivors during and following treatment, and thework adjustments cancer survivors use to better manage their work. Further, there is need to continue to expand our understanding of whether employment pathways of cancer survivors differ across countries due to different employment contexts. This study aims to:

(i) identify the symptoms, disclosure and work adjustments associated with working during treatment across a range of cancer groups.

(ii) identify the symptoms, disclosure and work adjustments associated with returning to work following treatment across a range of cancer groups.

\section{Method}

\section{Participants}

This was a cross-sectional study. 800 paper questionnaires were distributed to users registered with a UK-based cancer charity. An online version of the questionnaire was also made available on the charity's website. To allow for a breadth of response and the exploration of differential patterns in work, both cancer survivors and people with cancer were invited to complete the questionnaire. 210 paper questionnaires were returned and a further 118 were completed online $(\mathrm{N}=328)$. We were not able to compare the demographic and cancer-specific details of responders and non-responders. Respondents were predominantly female (76.5\%) and the respondents ranged from 18 to 68 years in age (average 50.37 years, $\mathrm{SD}=10.08$ ). In total, 45 different forms of cancer were identified and grouped into eight broad categories of diagnosis following advice from oncology specialists and drawing from previous research [7]. Full details of cancer types and treatment can be seen in Table 1. Respondents worked across job categories. A total of 199 different job titles were manually coded using the Standard Occupational Classification framework [22]. An overview is provided in Table 2. In terms of sizes of organisations represented, $6 \%$ of respondents were self-employed, $24 \%$ worked in small organisations (organisations employing between 2-49 employees), 29\% worked in medium sized organisations (between 50-1000 employees) and 34\% worked in large organisations (more than 1000 employees) at the time of their diagnosis.

\section{Measures}

The 33 item questionnaire included five sections: (i) Demographics including age, gender and occupation; (ii) Cancer-specific information which asked respondents to provide information about their cancer type, duration and treatment regime; (iii) Symptoms associated 
with cancer and its treatment included a series of one-item questions developed from the literature. Commonly reported side-effects of cancer and its' treatment were listed and can be seen in Table 4. These symptoms were preceded with the statement 'which of the following side effects were difficult to manage during and following your cancer treatment?' Response were reported on a yes or no dichotomy; iv) Disclosure of cancer at work. Single-item measures of disclosure to line manager and to colleagues were included. Disclosure was measured on a fourpoint response scale of yes, no, can't remember and not applicable. For the purposes of analysis, this was recoded into a dichotomous variable (where $1=$ yes); and (v) Work supports and adjustments sought and received (e.g. adjustment of physical environment, flexible/ alternative work arrangements). Items were developed from research within the wider fields of chronic illness and return to work [15-17] and included issues relating to rehabilitation policy (e.g. participation in a return to work interview) and work adjustments related to time discretion and physical load. Items were preceded with the statement 'Has your organisation offered you the following policies or services?' Work adjustment items were measured on a dichotomous response scale (yes/no). An open-text box at the questionnaire also invited respondents to note any further information of interest relating to their experience of cancer survivorship and work. The symptoms, disclosure and work adjustments reported by the respondents are summarised in Table 4 . The questionnaire was developed by the researchers as there were no measures available that could readily be incorporated to measure aspects of cancer survivorship and work. The questionnaire was piloted with a sample of cancer patients prior to distribution and took approximately $25 \mathrm{~min}$ to complete. The questionnaire can be provided by the authors. No significant differences were found on between paper-based and online completion on any measures.

\section{Analysis}

The factors associated with working during treatment and returning to work following treatment were calculated using univariate and multivariate logistic regression analyses (SPSS, version 10). In order to identify significant predictors of working during treatment (and thus simplify the relationships between a large number of variables), the data on each aspect of symptoms, disclosure and work adjustments, were separately entered into a univariate logistic regression analysis against the outcome variable of working during treatment. Those proving to be significant predictors at $\mathrm{p}<0.1$ level were then entered into multivariate stepwise logistic regression [23]. To identify the most parsimonious model of the data, the regression analysis was run a number of times, with the least significant variable removed from the model each time the regression was run until only a significant set of variables remained in the model. Parameter coefficients were monitored throughout this process to ensure important variables were not removed. The same procedure was followed against the outcome variable returning to work following treatment (Tables 5 and 6).

\section{Results}

An overview of cancer and treatments received by the sample are detailed in Table 1. The majority of the respondents were female (77\%) and accordingly the highest reported cancer incidence was breast cancer $(n=47)$. No significant differences were reported between breast cancer and other cancer groups on measures of symptoms or work adjustments and therefore further analysis is presented as a total group. Many of the respondents had received more than one type of treatment (28\% received two types, $28 \%$ three types and $15 \%$ all treatments). No significant differences between age groups were found for working during treatment or returning to work following treatment. The work patterns of the group are presented in Table 3 which shows the reportedwork status (and transitions) before treatment, during treatment and following treatment.

\section{Factors relating to work during treatment}

$30 \%$ of the sample continued to work during their treatment. Stepwise logistic regression identified a parsimonious model of the data $(\div=25.7, \mathrm{df}=3, \mathrm{p}<$.0001 $)$ that contained four significant correlates of working during treatment. The parsimonious model accurately classified 
$71 \%$ of the cases, with $94 \%$ of those reporting not working during treatment and $15 \%$ reporting working during treatment accurately classified. In the parsimonious model those who were able to work flexibly $(\mathrm{OR}=2.43, \mathrm{CI} 1.21-4.02)$ and who disclosed their cancer to their

colleagues (OR=3.03, CI 1.28-8.19) were more likely to continue working during treatment. Working during treatment was also associated with difficulties managing fatigue $(\mathrm{OR}=2.08, \mathrm{CI}$ 1.22-

\section{Factors relating to return to work following treatment}

$42.3 \%$ of the sample returned to work following their treatment. Stepwise logistic regression identified a parsimonious model of the data $(\div=33.0, \mathrm{df}=3, \mathrm{p}<.0001)$ that contained five significant correlates of returning to work following treatment. The parsimonious model accurately classified $69.8 \%$ of the cases, with $78 \%$ of those reporting not returning to work and $60 \%$ reporting returning to work accurately classified. Correlates of return to work included difficulties managing fatigue ( $\mathrm{OR}=1.49$, $\mathrm{CI} 1.42-6.18$ ), managing the stress of cancer

$(\mathrm{OR}=2.80,1.05-5.34)$, managing physical changes associated with cancer $(\mathrm{OR}=.46, \mathrm{CI} .13-.95)$, received advice from their doctor about work $(\mathrm{OR}=1.47$, CI 1.09-2.84) and return to work meeting with employer (OR 1.99, 1.2-5.09).

\section{Discussion}

The aim of this study was to further understanding of the experiences of work of cancer survivors. In line with previous research, the present findings indicate that working during treatment and returning to work is somewhat independent of cancer type and treatment type [12]. Whilst cancer and its treatment is known to impact on individuals psychological, cognitive and physical functioning $[8,10-15]$, the actual risk that these present to work during, or following treatment, can not be determined because of the cross sectional design of this study. However, it is Interesting that the symptom of fatigue was associated with both working during treatment and returning to work. In contrast to previous research [12], these findings also suggest that people working during treatment are more likely to report higher levels of fatigue compared to those who cease to work during this time. Furthermore, those returning to work are also more likely to report higher levels of fatigue and stress, managing these symptoms compared to those who do not return to work. This suggests that managing both illness and work may increase poor physical and psychological health outcomes. This highlights a need to understand the interaction of work and the management of illness during treatment, as well as the impact of treatment on one's ability to work. We suggest that compared with their actual functional limitations, there may be a mis-match of expectations versus ability to work. Some cancer survivors may perceive that their limitations are more significant than they are in reality, others may perceive that they can work harder than they can in reality. This could potentially have an impact on a person's management of work and on their employers' responsiveness to their needs. It is important that cancer survivors and their providers are aware of the impact the symptoms of cancer and its treatment and be encouraged to consider these in light of their current employment status and job role. However it is unclear at present how to detect those who experience these problems at work and those who do not.

Previous research indicates that employer-made work adjustments that directly accommodate work limitations reported by employees managing various chronic illnesses, enable them to not only manage their work, but maintain employment [20]. The findings from the current study add some support to the use of work adjustment. In this study, those with cancer who continue to work during treatment were more likely to receive adjustments in the form of flexible work arrangements than those who did not continue to work during treatment. Furthermore, those individuals who reported returning to work following treatment were significantly more likely to report being offered a return to work meeting with their employer. Importantly, those reporting difficulties managing physical changes associated with their cancer were less likely to return to work than those who did not report physical changes. This, in combination with the absence of physical environment adjustments reported by respondents, suggests that further work adjustments may be required to accommodate survivors who 
experience physical changes. Given the unique set of symptoms cancer survivor's report, future efforts need to investigate the effects of innovative accommodations. The current findings indicate that when work adjustments are tailored to meet the needs of those with cancer they are more likely to continue working or return to work. However, it is not known to what extent these work adjustments help to buffer the negative physical or psychological health outcomes such as fatigue and stress. Further longitudinal intervention-based studies are needed to delineate this relationship.

Only half of the respondents in this study reported that they received advice and guidance from their General Practitioner or their workplace, and less than a quarter were offered information to help them manage work issues associated with their cancer. These findings are consistent with qualitative research studies conducted in North America [6, 21]. The incomplete and inconsistent provision of information about the impact of cancer and its treatment on the ability to work represents a substantial gap in our understanding. Importantly, those returning to work following treatment were more likely to report that they had received advice from their doctor than those who did not. This highlights the importance of developing a clear framework for guidance to allow healthcare professionals to provide cancer survivors with the necessary support. This study is not without limitations and there is need to interpret these findings with caution. The largest group of participants were breast cancer patients (44\%) and this group far outweighed other cancer samples. Furthermore, participants were recruited through a support network. Not all cancer patients contact support organisations, and it may be that those who use such supports do so because they present higher levels of anxiety and illness-related distress. We were not able to compare the demographic and cancer-specific information of those who responded to the questionnaire and those who did not. Subsequently, our range of data collection may not be representative of all cancer survivors. Future research should aim to draw from clinical populations to sample the full spectrum of cancer survivors and followthe changes in employment status and the fluctuations of physical, social and psychological correlates during this time. Second, the full range of psychological, social and physical factors that may influence work were not examined here. Further research is required to develop a more detailed understanding of the psychological and social factors that actually predict continuance or return to work on the one hand, and the psychological consequences (e.g. anxiety and depression, illness distress, fear of illness reoccurrence) and the impact of workload, demands and support upon the well-being and functioning of cancer patients on the other. Whilst these limitations are recognised, the current study provides useful information about the experiences of cancer survivors managing work during and following treatment. Foremost, we hope that it sparks further research into this important but under-researched area.

\section{References}

1. Cancer Research UK. Statistics on the incidence of cancer 2001: Available from http://info.cancerresearchuk. org/cancerstats (25/03/2006).

2. American Cancer Association. Leading sites of new cancer cases and deaths - 2005 estimates. Inc Surveillance

Research; 2005.

3. Bradley CJ, Bednarek HL. Employment patterns of long-term cancer survivors. Psycho-Oncology 2002;11:188-98.

4. Spelten E, Sprangers M, Verbeek J. Factors reported to influence the return to work of cancer survivors: A literature review. Psycho-Oncology 2002;11:124-31.

Springer

J Occup Rehabil

5. National Cancer Institute. Annual report to the nation on the status of cancer 1975-2002. Journal of the National Cancer Institute; October 2005.

6. Maunsell E, Brisson C, Dubois L, Lauzier S, Franser A. Work problems after breast cancer: An exploratory 
qualitative study. Psycho-Oncology 1999;8(6):467-73.

7. Short PF, Vasey JJ, Tunceli K. Employment pathways in a large cohort of adult cancer survivors. PsychoOncology 2005;10:259-63.

8. Van derWouden JC, Greaves-Otte JGW, Greaevs J. Occupational reintegration of long-term cancer survivors. J Occup Med 1992;34:1083-9.

9. Feuerstein M. Cancer survivorship and work. J Occup Rehabil 2005;15(1):1-2.

10. Chirikos TN, Russell-Jacobs A, Hacobsen PB. Functional impairment and the economic consequences of female breast cancer. Womens Health 2002;36:1-20.

11. Cella D, Tross S. Psychological adjustment to survival from Hodkin's disease. J Consult Clin Psychology 1986;54:616-22.

12. Spelten ER, Verbeek JHAM, Uitterhoeve ALJ, Ansink AC, van der Lelie J, de Reijke TM, Kammeijer M, de Haes JCJM, Sprangers MAG. Cancer, fatigue and the return of patients to work-a prospective cohort study. Eur J Cancer 2003;39(11):1562-7.

13. Ahles TA, Saykin AJ, Furstenberg CT, Cole B,Mott LA, Titus-Ernstoff L, Skalla K, Bakitas M, Silberfarb PM. Quality of life of long-term survivors of breast cancer and lymphoma treated with standard-dose chemotherapy or local therapy. J Clin Oncol 2005;23(19):4399-405.

14. Minisini A, Atalay G, Bottomley A, Puglusu F, Piccart M, Biganzoli L. What is the effect of systemic anticancer treatment on cognitive function? Lancet Oncol 2004;5(5):273-82.

15. Greenwald HP, Dirks SJ, Borgatta EF, McCorkle R, Nevitt MC, Telin EH. Work disability among cancer patients. Soc Sci Med 1998;29(11):1253-59.

16. Munir F, Jones D, Leka S, Griffiths AJ.Work limitations and employer adjustments for employees with chronic illness. Int $J$ Rehabil Res 2005;28(2):111-7.

17. Thomson L,Neathey F, Rick J. Best practice in rehabilitating employees following absence due toworkrelated stress. Institute for Employment Studies, Research report 138. Brighton: UK; 2003.

18. Bradley CJ, Neumark D, Bednarek HL, Schenk M. Short-term effects of breast cancer on labor market attachment: Results from a longitudinal study. $J$ Health Econ 2005;24:137-60.

19. IRS. Rehabilitation: Return to work policies and practices. IRS Employ Rev 2001;741:40-7.

20. Baanders AN, Andries F, Rijken PM, Dekker J.Work adjustments among the chronically ill. Int $J$ Rehabil Res 2001;24:7-14.

21. Main DS, Nowels CT, Cavender TA, Etschmaier M, Steiner F. A qualitative study of work and work return in cancer survivors. Psycho-Oncology 2005;14:992-1004.

22. Standard Occupational Classification, Second edition, Her Majesty's Stationary Office, London; 1995.

23. Hosmer DW, Lemeshow S. Applied logistic regression. New York: Wiley \& Sons; 1998.

Springer 
Table 1 Characteristics of cancer survivors

\begin{tabular}{lccc}
\hline & \% Reporting & \\
\cline { 2 - 4 } & Total $(n=328)$ & Male 23\% $(n=77)$ & Female $77 \%(n=251)$ \\
\hline Age & & & 8.0 \\
Under 35 & 8.8 & 11.7 & 20.3 \\
$36-45$ years & 18.1 & 11.8 & 42.6 \\
46-55 years & 38.7 & 27.3 & 29.1 \\
56 years or above & 34.4 & 49.4 & 62.2 \\
Cancer site & & & 6.0 \\
Breast & 47.7 & 2.6 & 1.2 \\
Colorectal & 9.4 & 20.8 & 2.8 \\
Genital & 10.6 & 9.1 & 7.2 \\
Head and neck & 4.2 & 9.1 & 0.0 \\
Lymph & 10 & 19.5 & 2.4 \\
Prostate & 3.6 & 14.3 & 7.2 \\
Melanoma & 3.0 & 5.2 & 63.0 \\
Other & 9.1 & 15.6 & 57.0 \\
Treatment & & & 42.0 \\
Oral medication & 37.0 & 30.0 & 72.0 \\
Surgery & 65.0 & 54.0 & 56.0 \\
Chemotherapy & 59.0 & 47.0 & \\
Radiotherapy & 52.0 & & \\
\hline
\end{tabular}

Table 2 Occupation breakdown of respondents (total group)

\begin{tabular}{ll}
\hline Occupational group & \% Total \\
\hline Professional & 12 \\
Managerial/ Technical & 19 \\
Skilled/Operational - non-manual & 54 \\
Skilled/Operational - manual & 7 \\
Part-skilled & 7 \\
Un-skilled & Less than 1 \\
\hline
\end{tabular}

Table 3 Employment status before, during and following cancer treatment (total group)

\begin{tabular}{llll}
\hline & $\begin{array}{l}\text { Before } \\
\text { treatment }(\%)\end{array}$ & $\begin{array}{l}\text { During } \\
\text { treatment }(\%)\end{array}$ & $\begin{array}{l}\text { Following } \\
\text { treatment }(\%)\end{array}$ \\
\hline Working full-time & 59 & 15 & 35 \\
Working part-time & 27 & 19 & 29 \\
Self-employed & 6 & 3 & 4 \\
On sick leave & 1 & 43 & 12 \\
Unemployed & 1 & 2 & 3 \\
Retired & 0 & 13 & 5 \\
Unable to work & 3 & 1 & 6 \\
Other & 3 & 4 & 5 \\
\hline
\end{tabular}


Table 4 Summary of survivor symptoms, disclosure and work adjustments

\begin{tabular}{|c|c|c|}
\hline & $\begin{array}{l}\text { Working during treatment } \\
\text { total \% of group reporting }\end{array}$ & $\begin{array}{l}\text { Return to work following treatmen } \\
\text { total \% of group reporting }\end{array}$ \\
\hline Total number & $30 \%(n=97)$ & $42.3 \%(N=140)$ \\
\hline \multicolumn{3}{|l|}{ Gender $^{a}$} \\
\hline Male & 25 & 24 \\
\hline Female & 75 & 76 \\
\hline \multicolumn{3}{|l|}{ Survivor symptoms } \\
\hline Fatigue & 93.5 & 57.8 \\
\hline Stress of dealing with cancer & 48.5 & 43.9 \\
\hline Anxiety & 32.0 & 36.0 \\
\hline Loss of concentration & 36.1 & 33.1 \\
\hline Depression & 30.9 & 23.7 \\
\hline Pain & 29.9 & 21.6 \\
\hline Nausea/sickness & 37.1 & 15.8 \\
\hline Physical changes e.g. hair loss & 29.1 & 14.4 \\
\hline Disclosure to line manager & 56.7 & 63.6 \\
\hline Disclosure to colleagues & 93.8 & 90.7 \\
\hline \multicolumn{3}{|c|}{ Work supports and adjustments } \\
\hline $\begin{array}{l}\text { Paid time off to attend all medical } \\
\text { appointments }\end{array}$ & 40.2 & 43.0 \\
\hline $\begin{array}{l}\text { Paid time off to attend some } \\
\text { medical appointments }\end{array}$ & 88.0 & 44.1 \\
\hline $\begin{array}{l}\text { More than the legal minimum } \\
\text { sick leave }\end{array}$ & 37.1 & 36.4 \\
\hline Easy access to HR or OH support & 33.0 & 35.0 \\
\hline Work adjustment policies & 33.0 & 24.3 \\
\hline Counselling & 15.5 & 13.6 \\
\hline $\begin{array}{l}\text { Working fewer/flexible } \\
\text { contracted hours }\end{array}$ & 30.9 & 37.9 \\
\hline $\begin{array}{l}\text { Flexible/alternative working } \\
\text { arrangements }\end{array}$ & 39.2 & 29.3 \\
\hline $\begin{array}{l}\text { Adjustment of physical } \\
\text { environment }\end{array}$ & 16.5 & 12.9 \\
\hline Private health insurance & 9.3 & 7.9 \\
\hline $\begin{array}{l}\text { Return to work meeting with } \\
\text { employer }\end{array}$ & - & 27.1 \\
\hline $\begin{array}{l}\text { Offered any information } \\
\text { in managing work issues }\end{array}$ & 20 & 12.9 \\
\hline $\begin{array}{l}\text { Offered support in managing } \\
\text { work issues }\end{array}$ & 27.5 & 26.5 \\
\hline $\begin{array}{l}\text { Advice offered by doctor } \\
\text { about work }\end{array}$ & 49.3 & 49.3 \\
\hline
\end{tabular}

${ }^{a} 28 \%$ of all female respondents and 32.5 of all male respondents reported working during treatment. $42.6 \%$ of all female respondents and $42.9 \%$ of all male respondents reported returning to work following treatment.

Table 5 Predictors of working during treatment

\begin{tabular}{llll}
\hline Variable & $\beta$ & OR & $95 \% \mathrm{Cl}$ \\
\hline Disclosure to colleagues & $1.18^{* *}$ & 3.03 & $1.28-8.19$ \\
$\begin{array}{l}\text { Fatigue } \\
\begin{array}{l}\text { Paid time off to attend } \\
\text { some appointments }\end{array}\end{array}$ & $-.78^{*}$ & 2.08 & $1.22-3.85$ \\
$\begin{array}{l}\text { Flexible/ alternative } \\
\text { working arrangements }\end{array}$ & $.82^{* *}$ & .40 & $.30-87$ \\
\hline
\end{tabular}

Note, OR: Odds Ratio; $95 \%$ Cl: confidence intervals.

$" p<.05, " p<<.01$. 